\title{
$\mathrm{ZnO}$ 初期焼結体のネック半径
}

\author{
奥野雅史・迫川邦俊・光藤裕之 \\ (岡山理科大学理学部, 700 岡山市理大町 1-1)
}

\section{Neck Radius of ZnO Sintered-Bodies in Initial Stage}

\author{
Tadashi OKUNO, Kunitoshi SAKOGAWA and Hiroyuki MITSUDO \\ (Faculty of Science, Okayama University of Science, 1-1, Ridai-cho, Okayama-shi
}

700)

\begin{abstract}
First, sintering of two spheres of isotropic material which causes shrinkage is analyzed geometrically. The relation among the sphere radii, intersphere shrinkage and neck radius is expressed independently of ratio between the sphere radii. On the other hand, the larger ratio between sphere radii gives the larger selfexpansile pressure on the neck. Second, the sintering of crystallites of irregular shape as $Z n O$ powder is considered within the initial stage, and $P\left(r_{p}\right)$, the probability density of distribution of grain size $r_{p}$ and $P\left(r_{n}\right)$, that of neck radius $r_{n}$ are deduced statistically. If $r_{p}$ is given by the mean value of three elemental lengths independent of each other, $P\left(r_{p}\right)$ conforms to the $\chi^{2}$-distribution of 3 degrees of freedom and the average value $\bar{r}_{p}$ represents the distribution of $r_{p}$. Because $r_{n}$ depends on the linear intergrain-shirinkage $\Delta r$ as well, $P\left(r_{n}\right)$ conforms to the $\chi^{2}$-distribution of 4 degrees of freedom. The average value $\overline{r_{n}}$ represents the distribution of $r_{n}$. Thus, the sintering of the actual grains can be equated to that of spheres of isotropic material with the same radius $\overline{r_{p}}$ which cause the relative shrinkage of $\overline{\Delta r} / \overline{r_{p}}$. Ultimately, $\overline{r_{n}}$ and $P\left(r_{n}\right)$ are derived from the observed values of $\overline{r_{p}}$ and the relative density of sintered bodies. Third, the major grains construct the skeleton of sintered body and merge the minor grains in openings among the major grains during sintering. The arrangement of major grains through which electric current flows hardly varies. The decrease in electric resistance as sintering progresses is caused by the growth in each neck radius and each grain size. The arguments as above support the process for Hamano et al. to derive the dependence of bulk resistivity on the neck radius from the experimental results.

[Received June 10, 1988; Accepted July 22, 1988]
\end{abstract}

Key-words : Neck radius, Initial-stage sintering, $\mathrm{ZnO}$

\section{1. 緒 言}

焼結の初期段階において粒界に始点, ネックに終点を もつ物質移動が体積収縮と気孔率の減少をもたらす ${ }^{11}$. 浜野らは $\mathrm{ZnO}$ 焼結体について水銀アルキメデス法によ り実測した相対密度と走査型電子影微鏡写真観察から実 測した平均粒径を用いてネック半径を算出した ${ }^{22}$.

等方性の材質からなる半径 $r_{\mathrm{p}}$ の 2 球の焼結を考える. 粒界から拡散した原子が半径 $r_{n}$ のネックを形成し, 球 の中心間距離は $2 \Delta r$ だけ接近する． 2 球の中心を含む 断面におけるネックのくびれは，二つの円 $r_{\mathrm{p}}$ に接する 半径 $r_{\mathrm{p}}$ の円の弧であるとする，このとき，相対線収縮 $\Delta r / r_{\mathrm{p}}$ は次式により与えられている ${ }^{3 !}$.

$$
\frac{\Delta r}{r_{\mathrm{p}}} \fallingdotseq-\frac{r_{n}^{2}}{4 r_{\mathrm{p}}^{2}}
$$

（1）式に, 焼結体の相対密度 $d(\Delta r=0$ に対応する值 は $\left.d_{0}\right)$ と相対線収縮の関係を用いて

$$
-\frac{r_{n}{ }^{2}}{4 r_{\mathrm{p}}{ }^{2}} \doteqdot 1-\left(\frac{d_{0}}{d}\right)^{1 / 3}
$$

が与えられている.

この式は現実に反して $d_{0}>d$ であるときにのみ成立 する。これらの式を実際に用いるとぎにには，（1）式
の右辺及び ( 2 ) 式の左辺の負号を無視したものと考え ざるを得ない，また，(1) 式の導出に用いられた関係 $\Delta r \fallingdotseq r_{\mathrm{q}}$ も成立しないことが最近, 示されている4).

しかしながら，（2）式の左辺の負号を反転した式が, 実験結果の解析において, 不都合を生せず, むしろ, 大 いに有効であった ${ }^{22,5)}$ のは何故かという疑問が生じる. また, 実験に用いた $\mathrm{ZnO}$ 粉は球形でもなく, 等方性で もなく, 等半径でもない, 多数の粒の集合体であるにも 拘らず, 等方性, 等半径の 2 球について導いた関係式に よって, 焼結体の電気抵抗が有効に解析されたのは何故 かという疑問が生じる.

本論文は, これらの疑問に対する合理的な解答を与え ることを目的とする. 第 1 の疑問に関しては, 幾何学的 形状を表現する基本方程式を直接数值解析し, その結果 得られる関係の近似式を求めることにより, 解答を与え る. 第 2 の疑問に関しては, ランダムデータの統計処理 の方法に従って解答が与えられることを示す.

\section{2. 等方性異径 2 球の球間収縮とネック半径}

粒界あるいはその近くの粒内の原子が，ネック表面へ 拡散により移動して, 粒間線収縮とそれにより余った体 


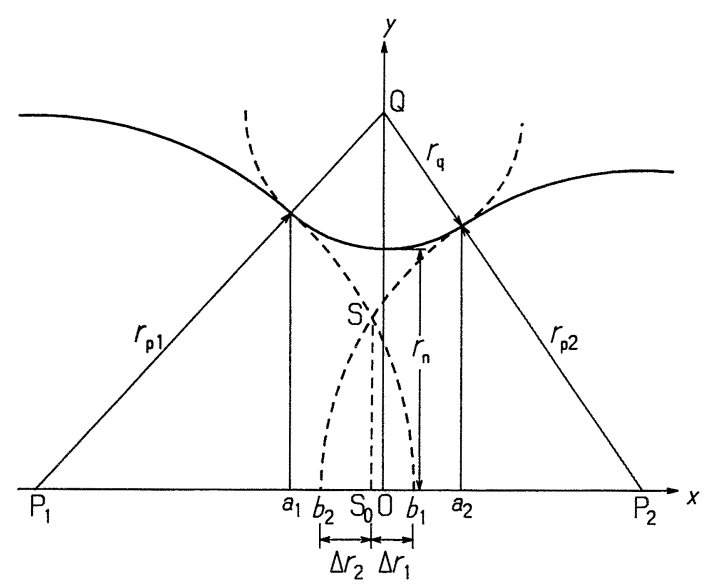

Fig. 1. A part of the principal section of two spherical particles which sinter with linear interparticleshrinkage.

積のネック表面への堆積により, ネック成長がもたらさ れると考える.

図 1 は相互に重なった二つの球の中心を通る断面の一 部を示す. 点 $\mathrm{P}_{1}$ 及び $\mathrm{P}_{2}$ はそれぞれ半径 $r_{\mathrm{p}_{1}}$ 及び $r_{\mathrm{p}_{2}}$ を もつ球の中心とし, 点 $\mathrm{P}_{1}, \mathrm{P}_{2}$ 及び $\mathrm{Q}$ を中心とし半径が $r_{\mathrm{p}_{1}}, r_{\mathrm{p}_{2}}, r_{\mathrm{q}}$ の円をそれぞれ円 $\mathrm{P}_{1}, \mathrm{P}_{2}$ 及び $\mathrm{Q}$ とよぶ. ここで円 $\mathrm{Q}$ は円 $\mathrm{P}_{1}$ 及び $\mathrm{P}_{2}$ に接するものとする． $x$ 軸 は点 $\mathrm{P}_{1}$ と $\mathrm{P}_{2}$ を通り, $y$ 軸は点 $Q$ を通るものとする. $a_{1}$, $a_{2}$ は円 $\mathrm{Q}$ が円 $\mathrm{P}_{1}$ 及び $\mathrm{P}_{2}$ と接する点の $x$ 座標とする. $b_{1}, b_{2}$ は, 円 $\mathrm{P}_{1}$ 及び $\mathrm{P}_{2}$ が，それぞれ， $\mathrm{P}_{1} \sim \mathrm{P}_{2}$ 間で $x$ 軸と交わる点の座標とする. $x$ 軸に垂直な断面のうち, 最小半径の円の半径をネック半径 $r_{n}$ とする. 円 $\mathrm{P}_{1}$ と $\mathrm{P}_{2}$ の交点 $\mathrm{S}$ から $x$ 軸におろした重直の交点を $\mathrm{S}_{0}$ とす る. $\mathrm{S}_{0}$ から座標 $b_{1}$ 点及び $b_{2}$ 点までの距離（正值）を それぞれ $\Delta r_{1}$ 及び $\Delta r_{2}$ とする.

直角三角形 $\mathrm{P}_{1} \mathrm{QO}$ 及び $\mathrm{P}_{2} \mathrm{QO}$ について成り立つ三平 方の定理式に

$$
B \equiv \Delta r_{1}+\Delta r_{2}=b_{1}-b_{2}
$$

を用いれば $b_{1}$ は

$$
b_{1}=\frac{2 r_{\mathbf{q}}\left(r_{\mathrm{p}_{2}}-r_{\mathrm{p}_{1}}\right)-B^{2}+2 B r_{\mathrm{p}_{2}}}{2\left(-B+r_{\mathrm{p}_{1}}+r_{\mathrm{p}_{2}}\right)}
$$

$r_{n} \geqq 0$ 及び $r_{\mathrm{q}} \geqq 0$ の条件下で $r_{n}$ は

$$
r_{n}=-r_{\mathrm{q}}+\left\{\left(r_{\mathrm{p}_{2}}+r_{\mathrm{q}}\right)^{2}-\left(r_{\mathrm{p}_{2}}+b_{2}\right)^{2}\right\}^{1 / 2}
$$

で与えられる。

直角三角形 $\mathrm{P}_{1} \mathrm{SS}_{0}$ 及び $\mathrm{P}_{2} \mathrm{SS}_{0}$ について成り立つ三平 方の定理式から， $r_{\mathrm{p}_{1}}>\Delta r_{1}$ を考慮して

$$
\Delta r_{1}=r_{\mathrm{p}_{1}}-\left\{{r_{\mathrm{p}_{1}}}^{2}-2 r_{\mathrm{p}_{2}} \Delta r_{2}+\Delta r_{2}{ }^{2}\right\}^{1 / 2}
$$

が得られる。

球 $\mathrm{P}_{1}$ について $a_{1}$ から $b_{1}$ までの体積を $V_{1}$, 球 $P_{2}$ に ついて $b_{2}$ から $a_{2}$ までの体積を $V_{2}, a_{1}$ から $a_{2}$ までの ネックの体積を $V_{n}$ とすると質量保存の条件は次式で表 される.

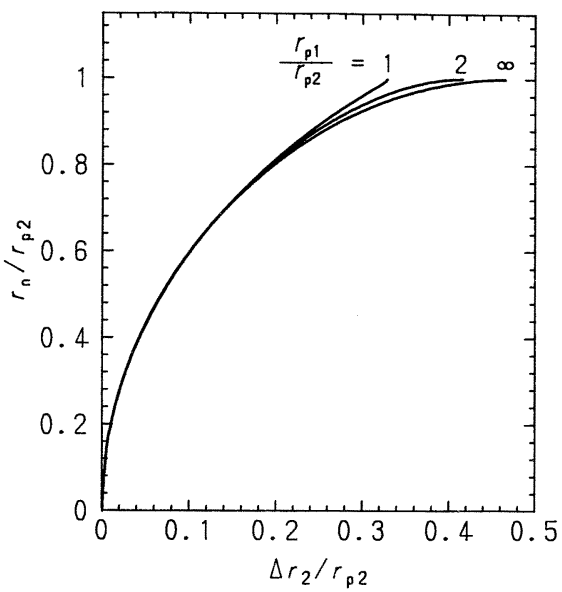

Fig. 2. Relative neck-radius $r_{n} / r_{\mathrm{p}_{2}}$ vs. relative linearinterparticle-shrinkage $\Delta r_{2} / r_{\mathrm{p}_{2}}$. Parameter $r_{\mathrm{p}_{1}} / r_{\mathrm{p}_{2}} \geqq 1$. The curves are obtained according to fundamental Eqs. ( 3 ) $-(10)$.

$$
V_{1}+V_{2}=V_{n}
$$

円 $\mathrm{P}_{1}, \mathrm{P}_{2}$ 及び $\mathrm{Q}$ の方程式を用いて， $V_{1}, V_{2}$ 及び $V_{n}$ は それぞれ次式で与亲られる.

$$
\begin{aligned}
V_{1}= & \pi \int_{a_{1}}^{b_{1}}\left\{r_{\mathrm{p}_{1}}{ }^{2}-\left(x+r_{\mathrm{p}_{1}}-b_{1}\right)^{2}\right\} \mathrm{d} x \\
= & \pi\left(a_{\mathrm{1}}-b_{1}\right)^{2}\left(r_{\mathrm{p}_{1}}+\frac{a_{1}-b_{1}}{3}\right) \\
V_{2}= & \pi \int_{b_{2}}^{a_{2}}\left\{r_{\mathrm{p}_{2}}{ }^{2}-\left(x-r_{\mathrm{p}_{2}}-b_{2}\right)^{2}\right\} \mathrm{d} x \\
= & \pi\left(a_{2}-b_{2}\right)^{2}\left(r_{\mathrm{p}_{2}}-\frac{a_{2}-b_{2}}{3}\right) \\
V_{n}= & \pi \int_{a_{1}}^{a_{2}}\left\{-\left(r_{\mathrm{q}}{ }^{2}-x^{2}\right)^{1 / 2}+r_{\mathrm{q}}+r_{n}\right\}^{2} \mathrm{~d} x \\
= & \pi\left[\left\{r_{\mathrm{q}}{ }^{2}+\left(r_{\mathrm{q}}+r_{n}\right)^{2}\right\} x-\frac{x^{3}}{3}\right. \\
& \left.-\left(r_{\mathrm{q}}+r_{n}\right)\left\{x\left(r_{\mathrm{q}}{ }^{2}-x^{2}\right)^{1 / 2}+r_{\mathrm{q}}{ }^{2} \arcsin \frac{x}{r_{\mathrm{q}}}\right\}\right]_{a_{1}}^{a_{2}}
\end{aligned}
$$

ただし，(10) 式は $|y| \leqq r_{\mathrm{q}}+r_{n}$ の条件下で求められた.

結局， $r_{\mathrm{p}_{1}}, r_{\mathrm{p}_{2}}, \Delta r_{1}, \Delta r_{2}, r_{n}$ 及び $r_{\mathrm{q}}$ の間の関係は, ネックの形状を規定する（3)，(4)，（5）及び（6) 式, 体積保存の条件式 (7)，（8)，（9)，(10）式（以 上を基本方程式とよぶことにする）を同時に満足させる 解として求まるが，これらの式を一つにまとめても簡潔 な表式にはならない. したがって数值解析を行って数値 曲線を求め, この曲線 (以後, 数值解曲線とよぶ) を表 現する簡単な近似式を求める.

$\Delta r_{2} / r_{\mathrm{p}_{2}}$ と $r_{n} / r_{\mathrm{p}_{2}}$ の関係を表す数值解曲線を図 2 に 示す. $\Delta r_{2} / r_{\mathrm{p}_{2}} \leqq 0.15$ かつ $r_{\mathrm{p}_{1}} / r_{\mathrm{p}_{2}} \geqq 1$ であるなら $r_{n} / r_{\mathrm{p}_{2}}$ は粒径比 $r_{\mathrm{p}_{1}} / r_{\mathrm{p}_{2}}$ にほとんど依存しない。ここで $r_{\mathrm{p}_{2}}$ は 相手の球よりも大きくない球の半径としなければならな w. 
まず $r_{\mathrm{p}_{1}} / r_{\mathrm{p}_{2}}=1$ のとき $\Delta r_{2} / r_{\mathrm{p}_{2}} \leqq 0.2$ の範囲について $\Delta r_{2} / r_{\mathrm{p}_{2}}$ と $r_{n} / r_{\mathrm{p}_{2}}$ の関係を次式で近似できる.

$$
\frac{\Delta r_{2}}{r_{\mathrm{p}_{2}}}=\frac{1}{3.29}\left(\frac{r_{n}}{r_{\mathrm{p}_{2}}}\right)^{2.14}
$$

この近似式の曲線を図 3 に破線で示す．比較のために, $r_{\mathrm{p}_{1}} / r_{\mathrm{p}_{2}}=1$ の条件下で求めた数值解曲線を実線で示し た. また図 2 に示す数值解曲線は $r_{\mathrm{p}_{1}} / r_{\mathrm{p}_{2}}$ にほとんど依 存しないからこの近似式は $r_{\mathrm{p}_{1}} / r_{\mathrm{p}_{2}}>1$ の場合にも適用 できる.

（1）式においてその負号を形式的に反転した式

$$
\frac{\Delta r}{r_{\mathrm{p}}}=\frac{1}{4}\left(\frac{r_{n}}{r_{\mathrm{p}}}\right)^{2}
$$

を図 3 に一点鎖線で示した.これら三つの曲線は類似し ており，(12）式を（11）式の簡素化式として認知する ことができる．そうすれば導出にかかわる不合理性が消 失するだけでなく，異径の粒間の初期焼結に適用範囲を 広げることができる.

直角三角形 $\mathrm{P}_{1} \mathrm{SS}_{0}$ 及び $\mathrm{P}_{2} \mathrm{SS}_{0}$ について成り立つ三平 方の定理式において, $\left(\Delta r_{2} / r_{\mathrm{p}_{1}}\right)^{2}$ 及び $\left(\Delta r_{1} / r_{\mathrm{p}_{1}}\right)^{2}$ の項 を省略すると次式が得られる.

$$
\Delta r_{1}=\frac{r_{\mathrm{p}_{2}}}{r_{\mathrm{p}_{1}}} \Delta r_{2}
$$

$\Delta r_{2} / r_{\mathrm{p}_{2}} \leqq 0.1$ ならば（13）式は原式に対するよい近似 であることが数值解によって確かめられている.

次に $r_{n} / r_{\mathrm{p}_{2}}$ と $r_{\mathrm{q}} / r_{\mathrm{p}_{2}}$ の関係を表す数值解曲線を図 4 に示す．この曲線は粒径比 $r_{\mathrm{p}_{1}} / r_{\mathrm{p}_{2}}$ に強く依存する．表 面張力 $\gamma$ が球粒に及ぼす自己緊縮圧（負の表面圧）は, 球半径 $r_{\mathrm{p}}$ に反比例する. 一方，ネックの表面圧が自己

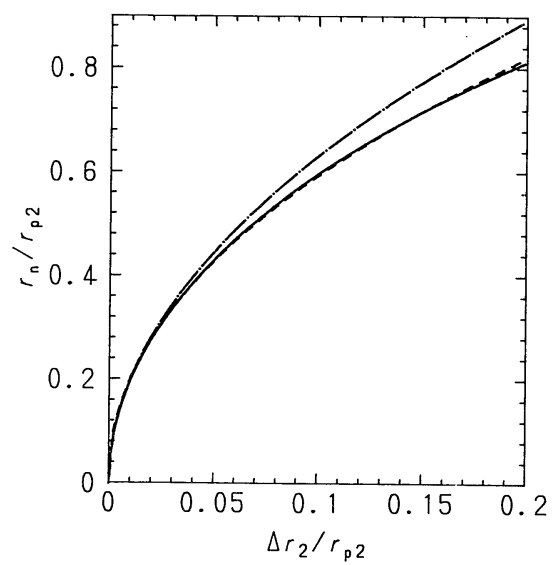

Fig. 3. Relative neck-radius $r_{n} / r_{\mathbf{p}_{2}}$ vs. relative linearinterparticle-shrinkage $\Delta r_{2} / r_{\mathrm{p}_{2}}$.

Solid line : curve obtained according to fundamental Eqs. ( 3$)-(10)$, as to $r_{\mathrm{p}_{1}} / r_{\mathrm{p}_{2}}=1$,

Broken line : curve obtained according to approximate Eq. (11),

Dashed-and-dotted line : curve obtained according to approximate Eq. (12).
拡張圧（正の表面圧）であるためには $r_{\mathrm{q}} / r_{n}<1$ でなけ ればならない.これら二つの圧力が協力して初期焼結の 駆動力となる. 図 4 において $r_{\mathrm{q}} / r_{n}$ は $r_{\mathrm{p}_{1}} / r_{\mathrm{p}_{2}}$ が増すに つれて減少する。このように大きい球に接する小さい球 の焼結駆動力は大きいから，大きい球は小さい球を併合 して成長する.このときの併合は再結晶過程によるもの であっても，粒界を介しての焼結であってもよいであろ う.

焼結初期は等半径の球が立方格子配列しているとき $r_{n} / r_{\mathrm{p}} \leqq 0.63$, 最密充填配列しているとき $r_{n} / r_{\mathrm{p}} \leqq 0.3$ の範囲とされている.これに反し， $r_{\mathrm{p}_{1}} / r_{\mathrm{p}_{2}}$ の大きい異 径の球の場合, $r_{n} / r_{\mathrm{p}_{2}}$ に課せられる制限範囲は大幅に 拡張される。

\section{3. 不規則粉粒焼結体のネック半径}

すりつぶした $\mathrm{ZnO}$ 粉を念頭において考える。粒形は 不規則で粒径は分布しており, 粒配列に整然性はない. 各微結晶粒は異方性をもち, 結晶面ごとに表面張力 $\gamma$ は異なる.この場合，前章の 2 球粒に関する取り扱いは 一定の制約を受ける. しかし, 粉粒数が極めて大きいこ とに由来して統計的取り扱いの対象となりうる.この章 では 2 粒間の局所的量と焼結体全体に関する巨視的量と の間の整合性を考察する.

粒配列に関して整然性は期待できなくとも次のような 秩序が考えられる．相対的に大きい粒同士は互いに接触 し成形体の巨視的形状とその寸法を規定する骨格をつく り, その隙間に相対的に小さい粒が配置される.ただし, 粒径と隙間径に分布があるから，ある局所での隙間粒が 他の局所での骨格粒よりも大きいこともありうる．上述 の初期焼結の限界条件は骨格粒同士の接合に関するもの

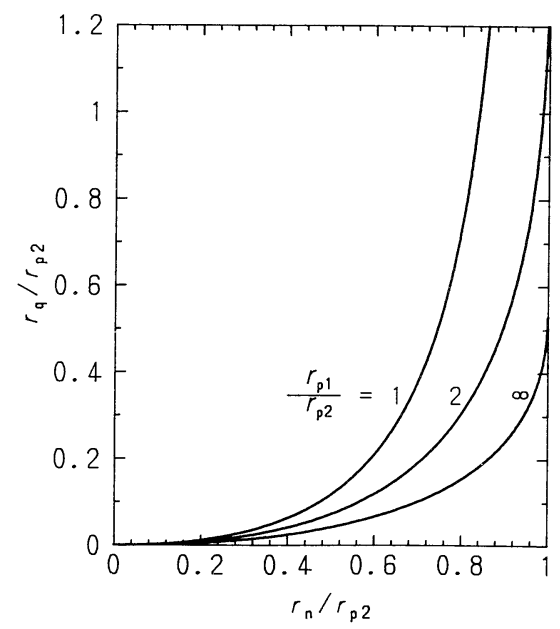

Fig. 4. Relative concave-neck-radius $r_{\mathrm{q}} / r_{\mathrm{p}_{2}}$ vs. relative convex-neck-radius $r_{n} / r_{\mathrm{p}_{2}}$. Parameter $r_{\mathrm{p}_{1}} / r_{\mathrm{p}_{2}} \geqq 1$. The curves are obtained according to fundamental Eqs. ( 3 )-(10). 
と考えられる． $r_{\mathrm{p}_{1}} / r_{\mathrm{p}_{2}}$ の大きい隙間粒と骨格粒との焼 結は骨格粒同士の焼結に優先して進行する.この過程は, 隙間粒を骨格粒が併合することによる骨格粒の成長と隙 間粒の減少をもたらすであろう。この結果, 小粒径域の 粒径分布密度の低下が生じるであろう。

$\mathrm{ZnO}$ 焼結体の平均粒径は相対密度 $d \leq 0.75$ の領域に おいては $d$ の増加に伴ってゆるやかに増加し, $d \geq 0.85$ の領域で極めて急激に増加している5 $. d \leq 0.75$ 域の粒 成長は主として隙間粒の骨格粒による併合によるもので あり， $d \geq 0.85$ では骨格粒子同士の合併が顕著になるも のと考えることができる．この場合，初期焼結において は，たとえ粒成長があっても，骨格粒子の数の減少は無 視できる、隙間粒はその近くにある骨格粒のうちのいず れかにダングリング接合し, 隙間粒同士の接合は少ない. この状況は, 焼結の第 2 期における Kaker モデルで表 現されるような円筒状の開気孔の形成を準備するものと 考えられる。したがって骨格粒子間の接合は, 初期焼結 の間, $\mathrm{ZnO}$ 焼結体の主要な電流通路を形成し, 隙間粒 の消滅は電流通路の配列を変更しない.

粒径分布の確率密度関数は粒の形状に強く依存するも のと考えられる.すべての粒が真球に近ければ，その寸 法要素は球半径のみである. ある半径值の出現がベルヌ 亿過程ならば，粒径は正規分布する，一方，球ではない 外形をもつ之き, 粒径は外形の特徴を決めるいくつかの 寸法要素の平均量として求められる. 多種の寸法要素の うち, たがいに独立な要素寸法は数種に限られる. 各要 素寸法が正規分布するとき粒径は $\chi^{2}$-分布する．粒形が 不規則であれば, 通常, 直交する 3 軸の長さを用いて $r_{\mathrm{p}}$ が求められるであろう。このとき自由度 $\nu=3$ である から $r_{\mathrm{p}}$ の確率密度分布 $P\left(r_{\mathrm{p}}\right)$ と平均粒径 $\overline{r_{\mathrm{p}}}$ はそれぞ れ次式で与えられる6).

$$
\begin{aligned}
& P\left(r_{\mathrm{p}}\right)=\left(\frac{2}{\pi}\right)^{1 / 2} \frac{r_{\mathrm{p}}{ }^{2}}{{c_{\mathrm{p}}}^{3}} \exp \left(-\frac{r_{\mathrm{p}}{ }^{2}}{2{c_{\mathrm{p}}}^{2}}\right) \\
& \overline{r_{\mathrm{p}}}=\left(\frac{2}{\pi}\right)^{1 / 2} 2 c_{\mathrm{p}}
\end{aligned}
$$

ここで長さのディメンションをもつ定数 $c_{\mathrm{p}}$ は $\overline{r_{\mathrm{p}}}$ の観 測值によって容易に決定できる。 $r_{\mathbf{p}}$ が与えられれば $r_{\mathbf{p}}$ の分布が決定される、 $\overline{r_{p}}$ は粒径を代表する.

粒径に分布のある焼結体において，任意の相接する 2 粒の組のそれぞれに（13）式が厳格に成り立つならば, 2 粒間の収縮率 $\left(\Delta r_{1}+\Delta r_{2}\right) /\left(r_{\mathrm{p}_{1}}+r_{\mathrm{p}_{2}}\right)$ は各組ごとに 同一ではないから, 粒間に圧縮応力, 引張応力あるいは 曲げ応力が局所的に分散して生じる. 更に, 粒形は不規 則であり粒径は粒の接合部付近の曲率半径を意味し, 表 面張力 $\gamma$ は結晶面によって異なる. これらの量も無秩 序に分布しており, (13)式が厳格に成り立つ余地はない。 一方, これらの局所的応力が小さくかつ無秩序に分布し ていれば, 巨視的な割れの発生は抑止され, 等方収縮が
実現する。このとき，ネックにおける正の表面圧は焼結 の主要な駆動力として,これらの局所的応力の影響下で, 作用する.

巨視的な等方収縮をもたらす 2 粒間線収縮 $\Delta r$ の代 表值を平均值 $\overline{\Delta r}$ とすれば, $\overline{\Delta r}=0$ のときの相対密度 $d_{0}$ に関し

$$
\frac{\overline{\Delta r}}{\overline{r_{\mathrm{p}}}}=1-\left(\frac{d_{0}}{d}\right)^{1 / 3}
$$

の関係式が成り立たねばならない。この式は局所的量 $\overline{\Delta r} / \overline{r_{\mathrm{p}}}$ と巨視的量 $d_{0} / d$ とを結びつけるものである. この関係は $r_{\mathrm{p}}$ に等しい等半径球の集合体において相接 する任意の 2 球の中心距離が $2 \overline{\Delta r}$ だけ接近し, ネック 半径 $r_{n}$ は一律に平均值 $r_{n}$ となる単純なモデルに等価で ある、この等価モデルに対しては, $\overline{\Delta r} / \overline{r_{\mathrm{p}}}$ 及び $\overline{r_{n}} / \overline{r_{\mathrm{p}}}$ について (11) 式と同様の関係

$$
\frac{\overline{\Delta r}}{\overline{r_{\mathrm{p}}}}=\frac{1}{3.29}\left(\overline{\frac{r_{n}}{r_{\mathrm{p}}}}\right)^{2.14}
$$

が成り立つ。

$\overline{r_{n}}$ は $\overline{r_{\mathrm{p}}}$ と $\overline{\Delta r}$ の関数であり， $\overline{\Delta r}$ は巨視的収縮に依 存して与えられる量である。 $\overline{\Delta r}$ は $\overline{r_{\mathrm{p}}}$ とは独立の寸法 要素であるから, 粒径の自由度が 3 であるとき, ネック 半径の自由度は 4 である. $r_{n}$ 分布の確率密度関数 $P\left(r_{n}\right)$ 及び平均ネック半径 $\overline{r_{n}}$ は次式で与えられる ${ }^{6 !}$.

$$
\begin{aligned}
& P\left(r_{n}\right)=\frac{r_{n}{ }^{3}}{2 c_{n}{ }^{4}} \exp \left(-\frac{r_{n}{ }^{2}}{2 c_{n}{ }^{2}}\right) \\
& \overline{r_{n}}=\frac{3}{2}\left(\frac{\pi}{2}\right)^{1 / 2} c_{n}
\end{aligned}
$$

ここで $\bar{r}_{n}$ が与えられるならば, 定数 $c_{n}$ を通じて $P\left(r_{n}\right)$ が決定される。したがって，分布するネック半径を $\overline{r_{n}}$ が代表することができる.（17）式を（16）式に用いて $\overline{\Delta r}$ を消去すれば，局所的量の代表值 $\bar{r}_{\mathrm{p}}$ 及び $\overline{r_{n}}$ は巨視 的量である相対密度と関係づけられる.

いま， 2 等径球間の值 $\Delta r, r_{\mathrm{p}}$ 及び $r_{n}$ を不規則形状 の粒の焼結体におけるそれぞれの值の平均值であるとし たうえで，(12）式を（17）式の代わりに用いることが

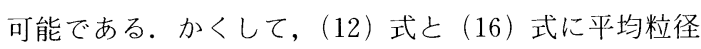
と相対密度のそれぞれの実測值を用いてネック半径の平 均值を求める浜野らの方法 ${ }^{21,5)}$ は合理的に裏付けをもつ ことになる。

(14) 式及び（18）式の確率密度分布を, それぞれ $r_{\mathrm{p}} / \overline{r_{\mathrm{p}}}$ 及び $r_{n} / \overline{r_{n}}$ について描いた結果を図 5 に示す. これらの曲線は非対称であって, 最大密度径は平均径よ りも小さく, 小径側よりも大径側の尾が長い.ただし, 自由度 4 の $P\left(r_{n}\right)$ 曲線は自由度 3 の $P\left(r_{\mathrm{p}}\right)$ 曲線よりも 対称性が高い. $P\left(r_{\mathrm{p}}\right)$ 曲線は粒径に対する個数基準の 頻度分布の標準的な曲線の特幑7) を呈している.

$\mathrm{ZnO}$ の初期焼結体を流れる電流はネックを通らねば ならない, 一方, ネックの電気比抵抗はネック半径に著 


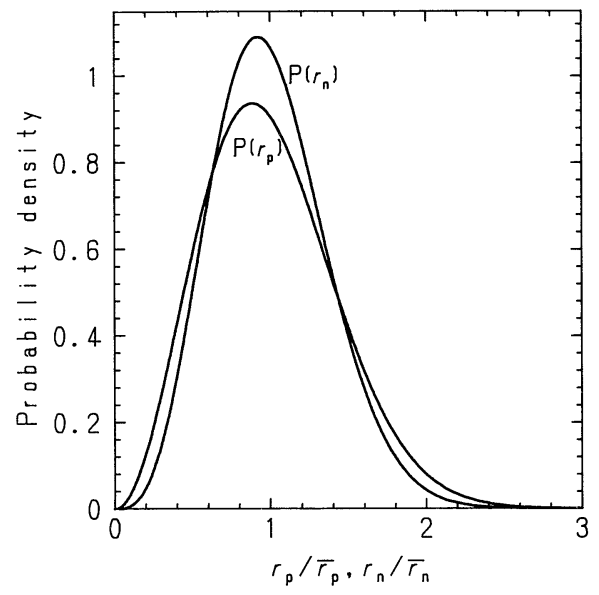

Fig. 5. Probability density $P\left(r_{\mathbf{p}}\right)$ as a function of grain size in unit of the average grain size $r_{\mathrm{p}} / \overline{r_{\mathrm{p}}}$ and probability density $P\left(r_{n}\right)$ as a function of neck radius in unit of the average neck radius $r_{n} / \overline{r_{n}}$.

しく依存する2),5),8).ここで与えられた（18）式及び（19） 式は, 焼結体の嵩比抵抗の平均ネック半径依存を算出す るために必要である。

しかしながら，骨格粒が隙間粒を併合する粒成長が進 行するとき, 上記の非対称性は強められる. 特に図示の 曲線における微小粒径の分布密度が焼結の進行に従って 低下するものと考えられる.

\section{4. 粒成長を伴う焼結体のネック半径の相対密度依存}

(16) 式は $\overline{\Delta r}=0$ のとき $d=d_{0}$ と仮定しているが, この式は $\overline{r_{\mathrm{p}}}$ が焼結の進行に伴って初期值を保つかどう かを不問に付している. 浜野らは初期焼結の段階におい てもゆるやかな粒成長のあることを観測している5.

一方，常圧焼結の場合においても成形時に加圧される ことが多い。浜野らの $\mathrm{ZnO}$ 試料は $1000 \mathrm{kgf} / \mathrm{cm}^{2}$ の静水 圧で成形されている ${ }^{2,5)}$ ．また，無加圧でも粉粒の集合 体においてネックが形成される. Ashby はこれを第 0 ステージと呼んでいる ${ }^{1)}$. 相対密度は, 少なくとも成形 体について測定される．厳密にいえば， $\Delta r=0$ 及び $r_{n}$ $=0$ (点接触) の状態に対応した相対密度は得られない. 相対密度の初期值 $d_{i}$ とそれに対応する平均粒半径 $r_{\mathrm{p}_{i}}$, 平均粒間線収縮 $2 \Delta r_{i}$ および平均ネック半径 $r_{n_{i}}$ が焼結 の進行に伴って，それぞれ $d, r_{\mathrm{p}}, 2 \Delta r$ 及び $r_{n}$ になる ものとする.ここで平均值符号は省略する. このとき相 対線収縮は次式で与えられる。

$$
\frac{\Delta r}{r_{\mathrm{p}}}=1-\left(1-\frac{\Delta r_{i}}{r_{\mathrm{p}_{i}}}\right)\left(\frac{d_{i}}{d}\right)^{1 / 3}
$$

この式の $\Delta r / r_{\mathrm{p}}$ 及び $\Delta r_{i} / r_{\mathrm{p}_{l}}$ に (17) 式の関係を用い れば, $r_{n}$ は

$$
r_{n}=1.745\left[1-\left\{1-\frac{1}{3.29}\left(\frac{r_{n_{i}}}{r_{\mathbf{p}_{i}}}\right)^{2.14}\right\}\left(\frac{d_{i}}{d}\right)^{1 / 3}\right]^{1 / 2.14} r_{\mathrm{p}}
$$

で与えられる. $d_{i}$ に対応して $r_{n_{i}} \fallingdotseq 0$ と見なせる成形体 が用いられるならば $r_{n}$ は $r_{\mathrm{p}_{i}}$ に依存しない簡単な式で 与えられる。

\section{5. 総 括}

$\mathrm{ZnO}$ 結晶粒のような非等方性物質の不規則形状粒か らなる粉体の初期焼結が巨視的に等方収縮をもたらす場 合について, 局所的な構造変化すなわち粒間収縮, ネッ ク成長及び粒成長を解析した。

粒径は自由度 3 の $\chi^{2}$-分布し, 平均粒径 $\bar{r}_{\mathrm{p}}$ はその分 布を代表する．粒間収縮の平均值 $\overline{\Delta r}$ は巨視的等方収 縮に対応する．ネック半径は粒径と粒間収縮に依存する から，その分布は自由度 4 の $\chi^{2}$-分布に従う。平均齐ッ ク半径 $\bar{r}_{n}$ はその分布を代表する. その結果, 不規則形 状粒の集合体の取り扱いは $\bar{r}_{\mathbf{p}}$ の等方性, 等半径球の焼 結の扱いに還元される.

粒とその配列の不規則性のために, 局所的応力の無秩 序分布が生じる。この応力の影響下で表面張力に駆動さ れて粒間接合が生じるから，二つの代表球の間をなめら かに接続するネック形状を考えることができる．計算の 結果, 粒半径, ネック半径及び粒間収縮を関係づける簡 単な近似式が導かれる. 浜野らが実際に用いた式 ${ }^{2)}$ は, この式によく似ており，その有効性に対する理論的裏付 けが与えられる.

焼結の進行に伴って, 隙間粒は骨格粒に併合されるか, 少なくともダングリング接合する. その結果, 粒成長が 生じ上記の $\chi^{2}-$ 分布の小径側の確率密度の低下をもたら す.しかし, 焼結体の巨視的形状と電流通路は骨格粒に よって与えられると考えられる. したがって, 焼結の進 行によってもたらされる嵩比抵抗の変化は, ネック半径 亡粒径の成長及び嵩体積の収縮のみによるとする浜野ら の取り扱い ${ }^{21,5)}$ が妥当之認められる.

\section{文献}

1) M.F. Ashby, Acta Metallurgica, 22, 275-89 (1974).

2）李 成元, 浜野健也, 中川善兵衛, 窯協, 93, 230-36 (1985).

3）橋本謙一, 浜野健也, “セラミックスの基礎”, 共立出版 (1975) pp. 230-31.

4）西谷邦雄, 長谷川保和, 東方正章, 窯協, 91, 483-87 (1983).

5）李 成元, 浜野健也, 中川善兵衛, 窯協, 94, 419-24 (1986).

6) J.S. Bendat, A. G. Piersol (徳丸英勝, 添田 喬, 紫田 碧, 中溝高好, 秋月影雄, 山川新二共訳), “ランダムデー 夕の統計的処理”, 培風館 (1972) pp. 97-103, Chap. 4 .

7）久保輝一郎, 神保元二, 水渡英二, 高橋 浩, 早川宗八 郎 編, “粉体 理論之応用”, 丸善 (1979) pp. 443-54.

8) 光藤裕之, セラミックス, 15，339-45 (1980). 